5 Wald NJ, Cuckle HS, Boreham J, Terzian E, Redman C. The effect of maternal weight on maternal serum alpha fetoprotein levels. Br $\mathcal{f}$ Obstet Gynaecol weight on mate.
$1981 ; 88: 1094-6$.

6 Haddow JE, Kloza EM, Knight GJ, Smith DE. Relation between maternal weight and serum alpha fetoprotein concentration during the second trimester. Clin Chem 1981;27:133-4.

7 Seller MJ. Prenatal screening for Down's Syndrome. Lancet 1984;i:1359.

8 McNay MB, Whitefield CR. Amniocentesis. Br J Hosp Med 1984;31:406-16.

Tabor A, Norgaard-Pedersen B, Jacobsen JC. Low maternal serum AFP and Down's Syndrome. Lancet 1984;ii:16

10 Cowchock FS, Ruch DA. Low maternal serum AFP and Down's syndrome. Lancet 1984 ; ii: $161-2$.

Guibaud S, Bonnet-Capela M, Germain D, Dumont M, Thoulon JM, Berland M Prenatal screening for Down syndrome. Lancet $1984 ; \mathrm{i}: 1359-60$.

serum AFP as a screening test for Down syndrome. Lancet $1984 ;$ ii $: 412$

13 Cuckle HS, Wald NJ. Principles of screening. In: Wald NJ, ed. Antenatal und neanatal screening. Oxford: Oxford University Press, 1984:1-22.
14 Brock DJH. Maternal serum alpha fetoprotein as screening test for Down

15 Houlsby WT. Maternal serum AFP as a screening test for Down syndrome. Lancet $1984 ; \mathrm{i}: 1127$

6 Rodeck $\mathrm{CH}$, Morsman JM. First trimester chorion biopsy. Br Med Bull 1983 39:338-42.

17 Brambati B, Simoni G. Diagnosis of fetal trisomy 21 in first trimester. Lance $1983 ; \mathrm{i}: 586$

18 Lueffler FE. Chorionic villus biopsy. Br 7 Hosp Med 1984;31:418-20.
19 Report of UK collaborative study on alpha fetoprotein in relation to neural tub defects. Maternal serum alpha fetoprotein measurement in antenatal screenin for anencephaly and spina bifida in early pregnancy. Lancet $1977 ; \mathrm{i}: 1323-32$.

20 Second report of the UK collaborative study on alpha fetoprotein in relation to neural tube defects. Amniotic fluid alpha fetoprotein measurement in antenatal dragnosis of ane
$1979 ;$ ii $652-62$

Accepted 4 April 1985)

\title{
Comparison of barium swallow and ultrasound in diagnosis of gastro-oesophageal reflux in children
}

\author{
D R NAIK, A BOLIA, D J MOORE
}

\begin{abstract}
Fifty one infants and older children with suspected gastro-oesophageal reflux entered a study comparing the diagnostic accuracy of a standard barium swallow examination with that of ultrasound scanning. All children were examined by both techniques.

In 40 cases there was unequivocal agreement between the examinations. Of the remaining patients, four had definite reflux by ultrasonic criteria but showed no evidence of reflux on barium swallow examination, four had positive findings on ultrasound but showed only minimal reflux on barium swallow, and one showed minimal reflux on ultrasound but had a negative barium meal result. In two children the ultrasound study was inconclusive.

Ultrasound has an important role in the diagnosis and follow up of patients under the age of 5 years with gastro-oesophageal reflux.
\end{abstract}

\section{Introduction}

Gastro-oesophageal reflux is an important and relatively common condition in infancy and childhood. It may be physiological, particularly in the younger age group,' and is self limiting and benign in most cases." It may, however, be one of the causes of failure to thrive, be a cause of repeated chest infections from aspiration, and be a factor in cot deaths. ${ }^{3}$ In addition to radiological means, 24 hour intraluminal oesophageal $\mathrm{pH}$ probe monitoring and isotope scintigraphy have been used for detecting gastro-oesophageal reflux. Recently a method using ultrasound has been described.

We report a study comparing the established method of barium swallow examination with ultrasound scanning in children with suspected gastro-oesophageal reflux.

\footnotetext{
Department of Radiology, Northern General Hospital, Sheffield S5 7AU

D R NAIK, DMRD, FRCR, consultant radiologis

A BOLIA, DMRD, FRCR, senior registrar in radiology

D J MOORE, MB, CHB, senior registrar in radiology

Correspondence to: Dr D R Naik.
}

\section{Patients and methods}

Fifty one children were examined for suspected gastro-oesophageal reflux. Their ages ranged from 4 days to 16 years, though most were under the age of 5 years. The main indications for investigation were vomiting, failure to thrive, repeated chest infections, and near miss infant death syndrome. The examinations were carried out by two operators independently. One operator carried out the barium swallow examination, which was followed later by the ultrasound examination, carried out by the second operator, who had no knowledge of the results of the barium examination. The technique of the ultrasound examination is detailed elsewhere. ${ }^{4}$ Barium swallow examinations were carried out using the standard technique."

\section{Results}

All children were examined by the two methods.

An empty lower part of the oesophagus is shown on ultrasound by three parallel lines, the outer lines representing the two walls and the middle line the collapsed lumen of the oesophagus (fig 1). The fundus of the stomach is easily visualised, being full of the gastric contents. The feed combined with microbubbles of air gives an easily recognisable ultrasonic pattern, comprising the transsonic fluid with scattered, bright speckled echoes representing the microbubbles. These bright echo speckles may be seen moving freely within the stomach.

During gastro-oesophageal reflux the gastric contents with a bright speckled echo pattern of microbubbles may be seen filling the lower oesophagus, when the third of the parallel lines representing the empty lumen will be lost. The two parallel lines will be seen apart from each other and the bright speckled echoes may be seen moving upwards from the stomach (fig 2). Often this is accompanied by "show" at the mouth, confirming the presence of gastro-oesophageal reflux.

Occasional reflux is common in normal children. The criteria used for diagnosing positive reflux were $(a)$ filling of the lower oesophagus on at least two separate occasions, and $(b)$ to and fro movement of the gastric contents between the lower oesophagus and the stomach.

The table gives the results of the barium swallow and ultrasound examinations of the 51 patients. There was agreement in 40 cases, comprising 15 positive, 24 negative, and one minimal positive result. Four patients had definite gastro-oesophageal reflux by ultrasonic criteria but barium swallow did not show any reflux. Four further patients showed positive reflux on ultrasound examination but barium swallow showed minimal reflux. One patient showed minimal reflux on ultrasound examination and had a negative barium swallow result.

There were two older children (13 and 15 years of age) in whom the ultrasound study was inconclusive. In neither case could the gastro-oesophageal junction be visualised. A possible explanation 
for this is the interposition of lung between the heart and the aorta in older children. There were, however, two other patients of 13 and 15 years in whom the gastro-oesophageal junction could be seen quite clearly.

\section{Discussion}

There are several methods available for the detection of gastro-oesophageal reflux in children and infants, including 24 hour intraluminal oesophageal $\mathrm{pH}$ probe monitoring, isotope scintigraphy, barium swallow, and ultrasound. The most widely used method is the barium swallow.

Both barium swallow and ultrasound examinations have a part to play in the detection and follow up of patients with gastro-oesophageal reflux. In this study there was a high rate of detection of gastro-oesophageal reflux by ultrasound in comparison with the barium swallow examination. There are two possible reasons for this. Firstly, the patient's normal feed is used, which may be more physiological. The feed is less
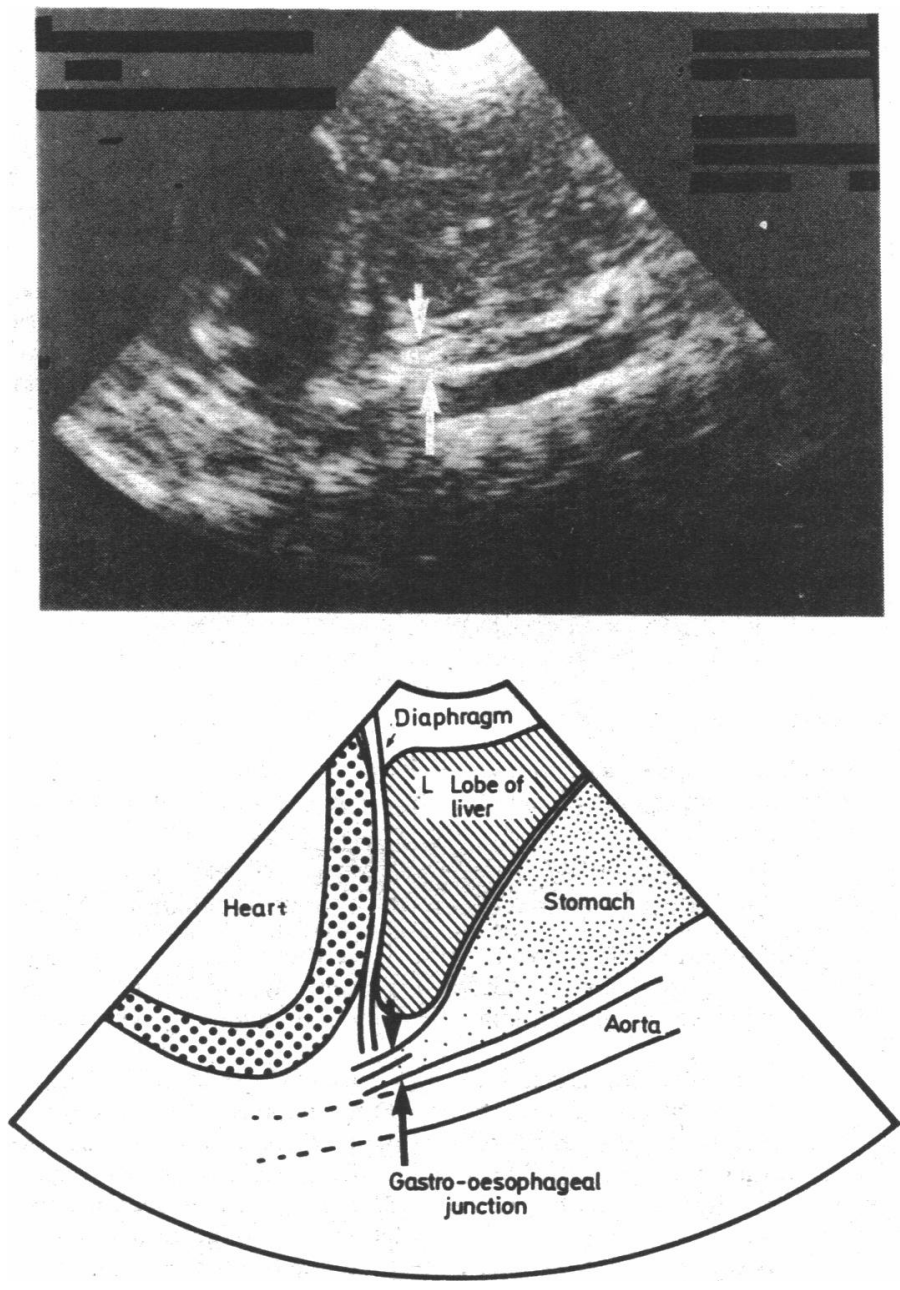

FIG 1-Hard copy from video recording together with line drawing showing position of normal cardia (arrowed) and adjoining structures.

Results of barium swallow and ultrasound examination

\begin{tabular}{lcccc}
\hline & \multicolumn{3}{c}{ Barium swallow result } & \\
\cline { 2 - 4 } & Positive & Negative & $\begin{array}{l}\text { Minimal } \\
\text { positive }\end{array}$ & Total \\
\hline Ultrasonic appearance & 15 & 4 & 4 & 23 \\
$\begin{array}{l}\text { Positive } \\
\text { Megative }\end{array}$ & 2 & 1 & 1 & 24 \\
Inconal positive & 17 & 29 & 5 & 51 \\
\hline \multicolumn{1}{c}{ Total } & & & & \\
\hline
\end{tabular}
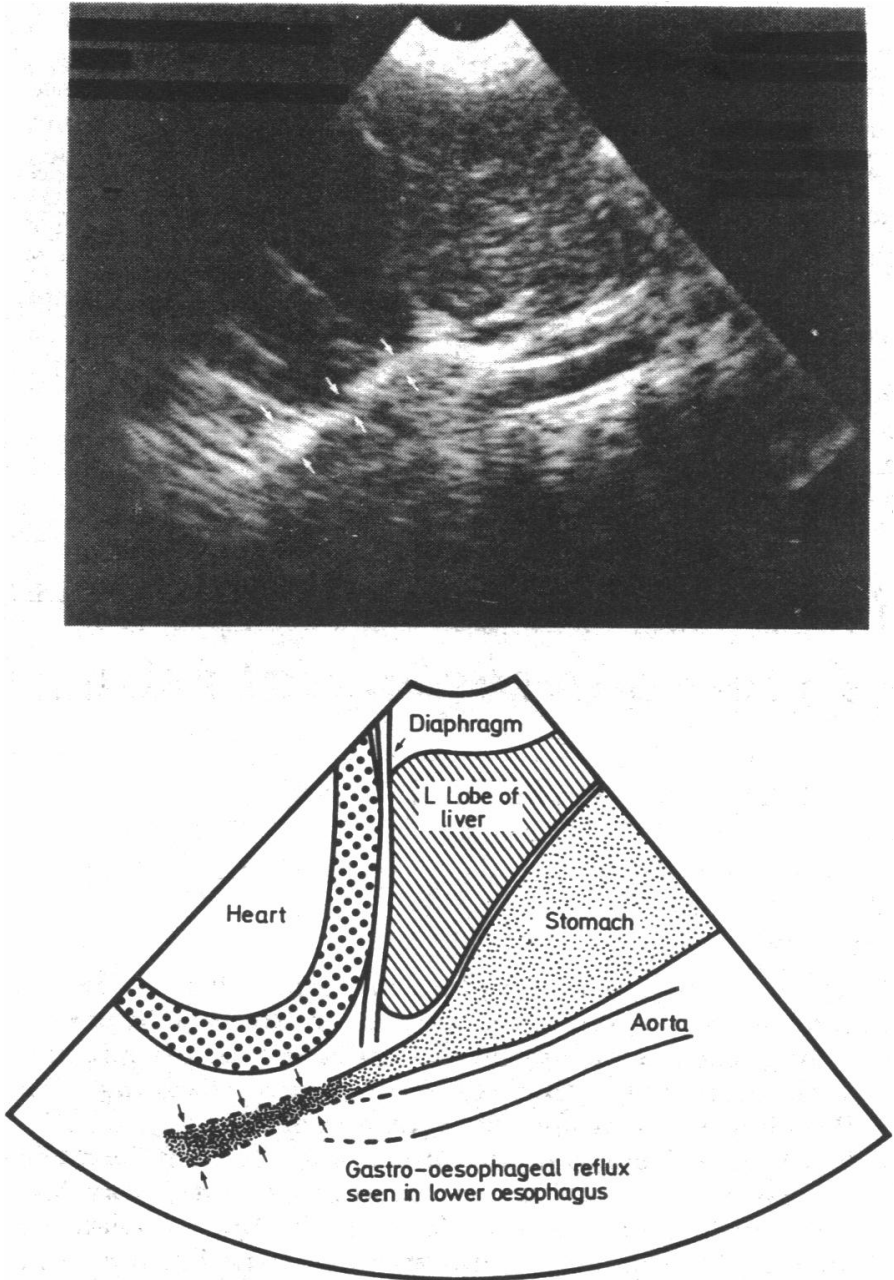

FIG 2-Hard copy from recording of case showing reflux into lower oesophagus (arrowed).

viscous than the barium mixture and may portray the true course of events. Secondly, long periods of continuous scanning may be employed by ultrasound, thus increasing the likelihood of detecting the intermittent nature of the reflux, which may be missed by short periods of $x$ ray screening. In one study $15^{\circ}$ o of cases of gastro-oesophageal reflux were missed by short periods of radiological screening. ${ }^{6}$

The established method of barium meal examination detects abnormalities not shown by the other methods-namely, (a) presence of hiatus hernia, $(b)$ peptic oesophagitis, $(c)$ stricture formation, and (d) incoordination of swallowing. Other abnormalities such as duodenal obstruction, midgut malrotation, and delayed gastric emptying, which may cause apparent gastro-oesophageal reflux, will be easier to diagnose by barium meal examination. These abnormalities, however, are rare. There is no age restriction for the barium examination, whereas ultrasound appears to be more useful in younger patients.

The use of ultrasound for detecting gastro-oesophageal reflux is attractive for several reasons. It is widely available, cheap to operate, and safe. The diagnosis appears to be reliable and reproducible. The escalating cost of diagnostic tests has to be borne in mind in the light of economies demanded by the cuts in health service budgets.?

From the results in our 51 cases the following five recommendations may be made. Firstly, all patients under the age of 5 years should undergo ultrasound examination as the initial investigation. If reflux is not detected it is unlikely to be shown by barium meal examination. Secondly, in infants in whom there is a strong clinical suspicion of other conditions associated with reflux a barium meal may be advisable to exclude the 
uncommon abnormalities mentioned above. Thirdly, ultrasound is the method of choice for follow up examinations in patients treated for reflux by medical means. Fourthly, the presence of reflux despite medical treatment is an indication for barium meal examination to exclude hiatus hernia and complications of reflux such as oesophagitis or stricture formation. Finally, the role of ultrasound in older children requires further clarification.

Both ultrasound and barium swallow examinations have an important part to play in patients with symptomatic gastrooesophageal reflux. Barium examinations are useful in the diagnosis of complications of reflux and in detecting uncommon conditions. We emphasise that most children do not require barium meal examination for diagnosis or during the subsequent management of reflux.
We are grateful to our paediatric colleagues for their cooperation in this study.

\section{References}

1 Carre IJ. Clinical significance of gastro-oesophageal reflux. Arch Dis Child 1984; $59: 911-2$.

2 Silverman A, Roy CC. Pediatric clinical gastroenterology. 2nd ed. St Louis: C V Mosby, 1983:10-1.

MacFadyne UM, Hendry GMA, Simpson H. Gastro-oesophageal reflux in Arch Dis Child 1983;58:87-91.

4 Naik DR, Moore DJ. Ultrasound diagnosis of gastro-oesophageal reflux. Arch Dis Child 1984;59:366-7.

5 Levick RK. In: Whitehouse GH, Worthington BS, eds. Techniques in diagnostic radiology. London: Blackwell Scientific Publications, 1983:325-35. Herbst JJ. Gastroesophageal reflux. F Pediatr $1981 ; 88: 859-70$ 7 Fowkes FGR. Containing the use of diagnostic tests. Br Med $\mathcal{f} 1985 ; 290: 488-9$. (Accepted 28 March 1985)

\section{SHORT REPORTS}

\section{Hypophosphataemic osteomalacia associated with prostatic carcinoma}

Prostatic carcinoma is common in the elderly, who often present with advanced disease. In $21 \%$ of patients the tumour may also be associated with hypophosphataemia. ${ }^{1}$ Osteomalacia associated with hypophosphataemia is well recognised in tumours of mesenchymal origin and may remit after resection of the tumour. ${ }^{2}$ However, hypophosphataemic osteomalacia associated with prostatic carcinoma, a tumour of endodermal origin, is rare and was first described in the United Kingdom by Hosking et al. ${ }^{3}$ We report our experience over two years of this lesser known but important association.

\section{Patients, methods, and results}

After seeing the index case we included in the study all patients with carcinoma of the prostate and secondary bone disease who were referred to the acute geriatric unit over two years. These patients underwent routine haematological tests and measurement of urea, electrolyte, chloride, bicarbonate, calcium, phosphate, and creatinine concentrations; alkaline phosphatase and acid phosphatase activities; and urinary phosphate and creatinine excretions. They also underwent isotopic bone scanning using technetium-99m disphosphonate. The renal phosphate threshold concentration was calculated by the method described by Walton and Bijovet. Serum total calcium concentration was adjusted to a reference albumin concentration of $47 \mathrm{~g} / \mathrm{l}$ using a method that gives a high correlation between measured and calculated calcium values over wide ranges of serum albumin values.

All patients with hypophosphataemia underwent bone biopsy, and serum parathyroid hormone and 25-hydroxyvitamin $D_{3}$ concentrations were estimated. Osteomalacia was diagnosed by bright line counting. The patients with osteomalacia were treated with alfacalcidol $(1 \mu \mathrm{g})$ once or twice daily, and the dose was adjusted depending on the clinical response and the serum

Mean $(S D)$ biochemical variables in patients with prostatic carcinoma and hypophosphataemic osteomalacia and controls (patients with prostatic carcinoma and normal serum phosphate concentration)

\begin{tabular}{|c|c|c|c|}
\hline & $\begin{array}{c}\text { Hypophosphataemic } \\
\text { group } \\
(\mathbf{n}=\mathbf{4})\end{array}$ & $\begin{array}{l}\text { Controls } \\
(n=11)\end{array}$ & $\begin{array}{c}\text { Laboratory } \\
\text { normal } \\
\text { range }\end{array}$ \\
\hline $\begin{array}{l}\text { Corrected serum calcium } \\
\text { (mmol/1) } \\
\text { Serum phosphate (mmol/1) } \\
\text { Alkaline phosphatase (IU/1) }\end{array}$ & $\begin{array}{c}2.40(0.26) \\
0.65(0.22) \\
1332.5(496)\end{array}$ & $\begin{array}{c}2.40(0.14) \\
1.01(0.28)^{* *} \\
340(340)^{*}\end{array}$ & $\begin{array}{l}2 \cdot 2-2 \cdot 6 \\
0 \cdot 8-1 \cdot 4 \\
30-100\end{array}$ \\
\hline $\begin{array}{l}\text { (mmol/1) } \\
\text { Acid phosphatase (IU/l) }\end{array}$ & $\begin{array}{l}0.4(0.07) \\
16.35(13.57)\end{array}$ & $\begin{array}{l}0.86(0.08)^{* *} \\
19.9(22.86)\end{array}$ & $\begin{array}{l}0 \cdot 8-1 \cdot 35 \\
0-2\end{array}$ \\
\hline $\begin{array}{l}\text { Serum 25-hydroxyvitamin } \\
\mathrm{D}_{3} \text { (nmol/1) }\end{array}$ & 12.5 & & $7 \cdot 5-75.0$ \\
\hline $\begin{array}{l}\text { Serum parathyroid normone } \\
\text { Serum creatinine ( } \mathrm{mmol} / \mathrm{l})\end{array}$ & $\begin{array}{l}<40 \\
108(23)\end{array}$ & $136(93)$ & $<120$ \\
\hline
\end{tabular}

$* \mathrm{p}<0.01, * * \mathrm{p}<0.001$.

Conversion: SI to traditional units-Calcium: $1 \mathrm{mmol} / 1 \approx 4 \mathrm{mg} / 100 \mathrm{ml}$. Phosphate

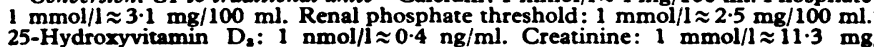
$1 \mathrm{mmol} / \mathrm{I}$
$25-\mathrm{Hydrax}$
$100 \mathrm{ml}$. calcium values. In addition, four of the five patients were given stilboestrol $1 \mathrm{mg}$ daily, and the fifth patient underwent orchidectomy. Eleven patients with extensive secondary bone disease but normal serum phosphate concentrations served as controls. One of the five patients with osteomalacia was excluded from the final analysis because he also had alcoholic liver disease and malnutrition. The table gives the biochemical data in the group with osteomalacia and the controls.

In all four patients bone pain and muscle weakness improved with treatment, as did the biochemical variables including the renal phosphate threshold concentration. The vitamin D treatment was inadvertently stopped in the index case, and this soon resulted in a fall in serum phosphate concentration and renal phosphate threshold concentration. In another patient a repeat bone biopsy showed complete healing of the osteomalacia after nine months of treatment.

\section{Comment}

This study shows that hypophosphataemic osteomalacia associated with prostatic carcinoma is not rare. Characteristic features of this condition are a low renal phosphate threshold concentration, normal parathyroid hormone and 25 -hydroxyvitamin $\mathrm{D}_{3}$ concentrations, but low 1,25-dihydroxyvitamin $\mathrm{D}_{3}$ concentration. ${ }^{1-3}$ All our patients had these features (except for the 1,25-dihydroxyvitamin $\mathrm{D}_{3}$ concentration, which was not measured) and symptoms of bone pain and muscle weakness.

Possible mechanisms are a phosphaturic effect, ${ }^{12}$ a humoral substance inhibiting the conversion of 25-hydroxyvitamin $D_{3}$ to 1,25-dihydroxyvitamin $D_{3}$, and oestrogens. ${ }^{5}$ As none of our patients was taking oestrogens during our study and three of the four patients responded to oestrogens with alfacalcidol, we conclude that oestrogen does not play a part in this condition.

We recommend that all patients with carcinoma of the prostate and hypophosphataemia should be thoroughly tested to exclude oncogenic osteomalacia, as the main symptoms are bone pain and muscle weakness due to the osteomalacia and these improve with alfacalcidol and other specific treatments for carcinoma of the prostate.

1 Lyles KE, Berry WR, Haussler M, Harrelson JM, Drezner MK. Hypophosphatemic osteomalacia: association with prostatic carcinoma. Ann Intern Med $1980 ; 93: 275-8$

Salassa RM, Jowsey J, Arnaud CD. Hypophosphatemic osteomalacia associated with "non-endocrine" tumors. N Engl f Med 1970;283:65-70.

Hosking DJ, Chamberlain MJ, Shortland-Webb WR. Osteomalacia and carcinoma 48:451-6.

4 Walton RJ, Bijvoet OLM. Nomogram for derivation of renal threshold phosphate

5 Citrin DZ, Elson P, Kies MS, Lind R. Decreased serum phosphate levels after

high-dose estrogens in metastatic prostate cancer. $A m \mathcal{F}$ Med 1984;76:787-93.

(Accepted 12 March 1985)

Whittington Hospital, London N19 5NF

P MURPHY, MB, MRCPI, senior research fellow

G WRIGHT, MB, MRCP, medical registrar

G S RAI, MD, MRCP, consultant physician and senior lecturer

Correspondence to: Dr G S Rai. 